\title{
The strange case of Mr. H. Starting dialysis at 90 years of age: clinical choices impact on ethical decisions
}

\author{
Giorgina Barbara Piccoli ${ }^{1,2^{*}}$, Andreea Corina Sofronie ${ }^{2}$ and Jean-Philippe Coindre ${ }^{2}$
}

\begin{abstract}
Background: Starting dialysis at an advanced age is a clinical challenge and an ethical dilemma. The advantages of starting dialysis at "extreme" ages are questionable as high dialysis-related morbidity induces a reflection on the cost- benefit ratio of this demanding and expensive treatment in a person that has a short life expectancy. Where clinical advantages are doubtful, ethical analysis can help us reach decisions and find adapted solutions.

Case presentation: Mr. $\mathrm{H}$ is a ninety-year-old patient with end-stage kidney disease that is no longer manageable with conservative care, in spite of optimal nutritional management, good blood pressure control and strict clinical and metabolic evaluations; dialysis is the next step, but its morbidity is challenging. The case is analysed according to principlism (beneficence, non-maleficence, justice and respect for autonomy).

In the setting of care, dialysis is available without restriction; therefore the principle of justice only partially applied, in the absence of restraints on health-care expenditure. The final decision on whether or not to start dialysis rested with Mr. H (respect for autonomy). However, his choice depended on the balance between beneficence and nonmaleficence. The advantages of dialysis in restoring metabolic equilibrium were clear, and the expected negative effects of dialysis were therefore decisive. Mr. $\mathrm{H}$ has a contraindication to peritoneal dialysis (severe arthritis impairing self-performance) and felt performing it with nursing help would be intrusive. Post dialysis fatigue, poor tolerance, hypotension and intrusiveness in daily life of haemodialysis patients are closely linked to the classic thrice-weekly, fourhour schedule. A personalized incremental dialysis approach, starting with one session per week, adapting the timing to the patient's daily life, can limit side effects and "dialysis shock".

Conclusions: An individualized approach to complex decisions such as dialysis start can alter the delicate benefit/ side-effect balance, ultimately affecting the patient's choice, and points to a narrative, tailor-made approach as an alternative to therapeutic nihilism, in very old and fragile patients.
\end{abstract}

Keywords: Elderly patients, Principlism, Narrative ethics, Haemodialysis, Palliative care

"Dialysis should follow life,

not life dialysis"

Interview with Sonia Angelini,

on renal replacement therapy for over 30 years.

\section{Background}

Staring dialysis at an advanced age is not only a clinical challenge but also an ethical one [1-4]. In fact, the

\footnotetext{
*Correspondence: gbpiccoli@yahoo.it

'Department of Clinical and Biological Sciences, University of Torino, Torino, Italy

${ }^{2}$ Nephrology, Centre Hospitalier Le Mans, Avenue Roubillard, 72000 Le Mans, France
}

advantages of starting dialysis at "extreme" ages are challenged by a growing body of data that show that, in patients with high comorbidity, the benefits may be offset by high dialysis-related morbidity, thus impacting on quality of life, without an advantage for survival [5-7].

Some authors have reported that with integrated clinical management, including nutritional management and optimization of symptomatic treatment, survival rates are comparable to those obtained with dialysis [7-12]. This option is often called "palliative care" or "conservative care" and some authors maintain that it should be offered 
as an alternative to dialysis to fragile patients with "terminal" end-stage renal disease (ESRD) [8-14]. The results are not always easy to interpret, as the choice of palliative care may be an indication of subtle fragilities or of a nihilist, depressive attitude, both associated with lower survival. Within these limits, a recent meta-analysis found equivalent one-year survival on palliative care and on dialysis [14].

The contraposition between dialysis care and conservative care may however be less Manichean. Just as the definition of alternative and complementary or allied medicines has shifted from being opposed to one another to being integrated, maximum "conservative care", in its semeiotic meaning of "preserving the residual kidney function" should probably be offered to all patients, in particular to those with the highest comorbidity [15-17]. Some groups, including ours, have tried to graduate the dialysis indications according to the individual's clinical needs, in an effort to progressively integrate the residual kidney function and thereby ensure a smooth shift from pre-dialysis to dialysis care [18-30].

In this report we will analyse a clinical case, referred to as "Mr H".

In addition to the analysis of its clinical issues, looking at a case with an eye to the four principles of principlist ethics, integrated when necessary with an individual "narrative ethics" approach, can help clinicians decide what to do and how to support patients in critical phases of their disease.

Therefore, the case of Mr. $\mathrm{H}$ will be discussed on the basis of the four principles, to exemplify how the modulation of clinical options can change the beneficence/ non-maleficence balance, thus affecting ethical reasoning and the patient's choice [30-33]. Differently from other recently reported cases, $\mathrm{Mr}$. $\mathrm{H}$ received extensive counselling, and all the options, including "non dialysis" were thoroughly explained and examined; therefore we will focus our discussion on how the way dialysis is done can influence the decisional process $[1,2,4]$.

Furthermore, we will discuss how combining principlism with narrative ethics can furnish practical suggestions, in the context of patient-centred, individualized medicine [33-36].

\section{Case presentation}

The case we discuss is that of $\mathrm{Mr} . \mathrm{H}$, a 90-year-old patient with end-stage kidney disease, diagnosed as nephroangiosclerosis. This clinical diagnosis was based on a long-standing history of hypertension, the presence of diffuse signs of vascular disease, the absence of severe proteinuria, relevant haematuria or systemic symptoms suggesting a different cause of chronic kidney disease (CKD). Furthermore, up to the last CKD phase, the progression trajectory had been relatively slow, after which a relatively rapid increase in creatinine was observed in the course of 1 year (creatinine $1.52 \mathrm{mg} / \mathrm{dl}$ in February 2007, $2.5 \mathrm{mg} / \mathrm{dl}$ in November 2015, $2.7 \mathrm{mg} / \mathrm{dl}$ in January 2016, $3.1 \mathrm{mg} / \mathrm{dl}$ in March 2016).

In June $2016 \mathrm{Mr}$. H was hospitalised for a further reduction in kidney function, probably after an oligosymptomatic infection (C-reactive protein $71 \mathrm{mg} / \mathrm{l}$, fibrinogen: $7.44 \mathrm{~g} / \mathrm{l})$. At hospitalisation, serum creatinine had reached $7.5 \mathrm{mg} / \mathrm{dl}$, with severe acidosis (bicarbonate $15 \mathrm{mEq} / \mathrm{l}$ ) and anaemia (haemoglobin $7.9 \mathrm{~g} / \mathrm{dl}$ ). The possibility of a cholesterol emboli syndrome was also considered, on account of the diffuse vascular disease observed, but no eosinophilia, livedo reticularis or skin lesions were present.

At hospitalisation, the patient's weight was $80.7 \mathrm{~kg}$, for a body mass index of $30.7 \mathrm{Kg} / \mathrm{m} 2$ (height $1.62 \mathrm{~m}$ ), with no clinical signs of malnutrition; severe arthrosis and diffuse leg hyperkeratosis were also part of the clinical picture. During hospitalisation his general metabolic balance improved, but his serum creatinine stabilised between 6.0 and $7.0 \mathrm{mg} / \mathrm{dL}$.

At 90 years of age, Mr. $\mathrm{H}$ lived alone, with help from the social services for home management; he received a hot meal at noon from a retirement home (in line with the usual organization of French home support). The meal served as a basis for lunch and supper, supplemented with bread, potatoes, or cheese. He kept a garden and claimed to grow the best potatoes in the area.

While the usual prognostic indexes may not be of great help in patients in advanced old age, his Charlson index was 9 (high comorbidity, two-year survival probability of $30 \%$ ), i.e. a comorbidity mainly linked to age and end-stage kidney disease. Perhaps more importantly, given the close link between nutritional status and survival, his SGA (subjective global assessment) score was A (well nourished) and his MIS (malnutrition inflammation score) index was 3 (optimal).

With this background, the decision on whether or not to start dialysis was discussed, including the options of peritoneal dialysis, haemodialysis and a low-protein diet. Since Mr. H suffered from severe arthrosis, which would have prevented self-performance, and did not receive nursing care, it was decided that peritoneal dialysis should not be undertaken. Haemodialysis was considered as a potential option that could be undertaken if absolutely necessary, and a low-protein diet was chosen as the best initial option. His diet was adapted to make up a $0.6-0.8 \mathrm{~g} / \mathrm{Kg} /$ day moderately restricted, plant-based, but not fully vegan, low-protein diet that was supplemented with amino and ketoacids (1 Ketosteril pill for each $10 \mathrm{Kg}$ of body weight), to avoid malnutrition. Given the low probability of creating a functioning arteriovenous 
fistula, the placement of a tunnelled catheter was decided on in case dialysis became necessary.

Close follow-up was started, with monthly or twice monthly controls; however, acidosis was very difficult to control and rapid unpredictable weight gain was observed, requiring frequent hospitalisation, in spite of good nutritional compliance, and good blood pressure control.

From a theoretical point of view, treatment should maximize survival and improve quality of life while the negative effects produced should be minimal. This was not fully clear in our patient and the medical and nursing staff was concerned about the clinical implications of dialysis start in a patient of Mr. H's age; therefore there were further extensive discussions of treatment options, presented by the nurses and a psychologist. After this step, Mr. H, who had initially agreed to start dialysis was reported to refuse treatment, considering it incompatible with his daily routine. Subsequent conversations revealed that the underlying problem was missing his midday meal: "If I come to dialysis, I won't be home at noon; and if I'm not home at noon, the people who deliver my meals will not find me, and if they do not deliver my meals, I won't have anything to eat. I'm 90, I have severe arthrosis, and I'm no longer able to cook my meals myself. And I want to eat."
Identification of the communication problem (presentation of a standard haemodialysis technique of 4 hours three times per week, instead of a tailored incremental approach) led to an empiric "narrative" compromise, with a prescription of $2.30-3.0 \mathrm{~h}$ of dialysis, one session per week, combined with a 30-min change in the delivery time of his meals. Mr. $\mathrm{H}$ felt that this arrangement was compatible with his needs.

At the time of the present report, $\mathrm{Mr}$. $\mathrm{H}$ is alive and in good clinical condition. He is still on a once-daily schedule. Some relevant biochemical data are reported in Table 1. They show good overall clinical and biochemical stability, which would probably have been difficult to achieve without treatment: even if the formulae for eGFR calculation are not precise in advanced old age, $9 \mathrm{mg} / \mathrm{dL}$ of serum creatinine corresponds to $5-6 \mathrm{~mL} /$ min of GFR according to the formulae employed, and the pre-dialysis level remains quite stable, thus suggesting that we were not dealing with an acute and reversible kidney injury on the basis of a chronic renal disease (Table 1).

The main electrolytes are normal in the predialysis phase, except for mild acidosis (Bicarbonate between 17 and $20 \mathrm{mEq} / \mathrm{L}$ ); parathyroid hormone is in the 100 $300 \mathrm{ng} / \mathrm{mL}$ range and brain natriuretic peptide is between 80 and $120 \mathrm{pg} / \mathrm{ml}$, in line with the absence of fluid

Table 1 Clinical and biochemical data before and after dialysis start

\begin{tabular}{|c|c|c|c|c|}
\hline & Predialysis (last biochemical data) & 1 month of $\mathrm{HD}$ & 6 months of $\mathrm{HD}$ & 12 months of $\mathrm{HD}$ \\
\hline \multirow[t]{4}{*}{ Hospitalisations } & 23/06/2016 to 08/07/2016 & \multirow[t]{4}{*}{ none } & \multirow[t]{4}{*}{ none } & \multirow[t]{4}{*}{ none } \\
\hline & 08/08/2016 to $13 / 08 / 2016$ & & & \\
\hline & 03/10/2016 to $7 / 10 / 16$ & & & \\
\hline & $\begin{array}{l}\text { 24/10/2016 to 01/11/2016 (dialysis } \\
\text { start) }\end{array}$ & & & \\
\hline Autonomy & Preserved & Preserved & Preserved & Preserved \\
\hline Oedema (clinical) & Yes & $\begin{array}{l}\text { No Weight loss on dialysis } \\
0.5-1 \mathrm{~kg}\end{array}$ & $\begin{array}{l}\text { No Weight loss on dialysis } \\
1-1.5 \mathrm{~kg}\end{array}$ & $\begin{array}{l}\text { No Weight loss on dialysis } \\
0.5-1 \mathrm{~kg}\end{array}$ \\
\hline BP control & $\begin{array}{l}\text { Difficult }(160-170 / \\
90-100 \mathrm{mmHg})\end{array}$ & $\begin{array}{l}\text { OK (pre: 130-150/ 70- } \\
\text { 90-mmHg) }\end{array}$ & $\begin{array}{l}\text { OK (pre: 130-150/ 70- } \\
\text { 90-mmHg) }\end{array}$ & $\begin{array}{l}\text { OK (pre: 130-150/ 70- } \\
\text { 90-mmHg) }\end{array}$ \\
\hline $\mathrm{BMI}(\mathrm{Kg} / \mathrm{m} 2)$ & 31.7 & 33.09 & 33.29 & 33.71 \\
\hline \multirow[t]{2}{*}{ BUN mg/dL } & \multirow[t]{2}{*}{122.4} & 86.24 pre & 96.88 pre & 113.96 pre \\
\hline & & 34.72 post & 41.16 post & 50.68 post \\
\hline \multirow[t]{2}{*}{ Albumin $\mathrm{g} / \mathrm{dL}$} & \multirow[t]{2}{*}{3.5} & 3.2 pre & 3.6 pre & 3.3 pre \\
\hline & & 3.3 post & 4.0 post & 3.6 post \\
\hline Haemoglobin g/dL & 13.4 & 11.5 & 11 & 11.1 \\
\hline \multirow[t]{2}{*}{ Bicarbonate $\mathrm{mmol} / \mathrm{L}$} & \multirow[t]{2}{*}{18} & 24 pre & 27 pre & 27 pre \\
\hline & & 26 post & 28 post & 22 post \\
\hline \multirow[t]{2}{*}{ Creatinine $\mathrm{mg} / \mathrm{dL}$} & \multirow[t]{2}{*}{9.45} & 6.32 pre & 5.71 pre & 8.09 pre \\
\hline & & 3.05 post & 3.35 post & 3.72 post \\
\hline
\end{tabular}


overload (little need for weight loss in dialysis, on furosemide $120 \mathrm{mg} /$ day). Haemoglobin has been kept on target (10-11 g/l) with recombinant erythropoietin; blood pressure has been controlled with Lercanidipine $20 \mathrm{mg}$, Nebivolol $5 \mathrm{mg}$ and Urapidil $120 \mathrm{mg}$. Serum albumin is well preserved, and the patient's "dry weight" increased after the start of dialysis. Mr. $\mathrm{H}$ is still on a $0.8 \mathrm{~g}$ of protein $/ \mathrm{Kg} /$ day diet, supplemented with Ketosteril (1 each $10 \mathrm{Kg}$ of $\mathrm{BW}$ ).

Meanwhile, he has celebrated his ninety-first birthday. His good clinical and psychological adaptation to dialysis treatment have made the medical and nursing group confident that it will be possible to extend this option to a twice weekly schedule, with limited dialysis time (2.5$3 \mathrm{~h}$ ) if necessary in the future.

\section{The principlist approach}

In this first part of the discussion we analyse the case of our ninety-year-old patient on the basis of the four principles of justice, autonomy, beneficence and nonmaleficence, as an integration to the clinical discussion and as a way to highlight the points in which a flexible clinical approach, in line with personalized medicine, can support a patient's decisions.

\section{Justice}

There are several ways to consider justice from an ethical point of view in medicine; although they are all legitimate, they differ markedly [37-44].

A "social" reading of justice sees it as the fair distribution of opportunities and resources between individuals, with particular attention to competing situations, in which the choice of care for one patient may mean a lack of availability of care for another [38-44].

Since in the setting of in which $\mathrm{Mr}$. $\mathrm{H}$ received care (France) dialysis treatment is available without limitation for all patients needing it, we considered that he had the right to be treated. While the risk of overtreating and of a futile use of resources persists, our patient is not the only nonagenarian on dialysis, nor the oldest one reported in the literature, in which positive results have been recorded, challenging an age-centred policy [45-48].

On a more general basis, our case elicits somewhat contrasting reflections on the complex relationship between physicians' time, delivery of resources and the cost efficiency of health care services. In this context, justice may have a more pragmatic connotation. In settings of limited resources, in which dialysis treatment is not freely available, or is limited by logistic reasons, a lower number of dialysis sessions per patient makes it possible to treat more individuals, and optimise access to care. In contrast, in high-resource settings, in which dialysis is a well-established right, and often a quite cost- efficient treatment, a flexible approach to dialysis sessions is a departure from a rigid "thrice-weekly" organisation, thus reducing the economic efficiency of the system. A tailor-made dialysis system is, of course, not incompatible with economic efficiency, but as a rule, flexibility and cost-cutting are inversely related, and treatments that differ from a time-honoured routine usually require additional control, which is obviously more demanding.

In this regard, personalized medicine, increasingly advocated as the best model of care, emphasizes the ethical issues physicians face: is their primary responsibility to guarantee the individual patient's rights, or to ensure the economic efficiency of the health care system?

On an organizational basis, we need to take into account that personalization requires medical time, as does discussion; while the temptation to dismiss this issue by arguing that "time constraints make it impossible to follow all patients in this way" is evident, personalized medicine offers a precious tool not only for defending the autonomy of physicians' choices, but also for ensuring that time is available for attaining this qualitative goal.

A "legal" interpretation of the sense of justice sees it as synonymous with laws. In this context, Mr. H's right to treatment is guaranteed by French law, as is his decision not to undertake dialysis treatment if he does not wish to [49].

In addition, justice can be seen as a moral/ethical right, taking religious beliefs into account. In this regard, Mr. H's religious beliefs may have influenced his decision on whether or not to undertake a potentially complex treatment, but once more, the decision was his, and offering dialysis to an elderly, independent and competent person does not challenge current ethical or moral norms [50-53].

\section{Respect for autonomy}

In western countries, respect for the patient's autonomy is usually considered to be the most important of the four principles, which is of particular importance when different principles are in conflict or are not syntonic, as in the case of $\mathrm{Mr}$. $\mathrm{H}$, in which the balance between beneficence and non-maleficence is particularly delicate $[54,55]$.

In fact, in the absence of an a priori decision in favour or against starting dialysis, the choice $\mathrm{Mr}$. $\mathrm{H}$. made depended on how he saw the balance between beneficence and non-maleficence, the latter consisting in the risks and side effects involved in dialysis.

A discussion of the impossibility of offering patients wholly unbiased information, as it is inevitable that physicians' or nurses' convictions will influence how they explain options to patients, and of the role of the "way we 
say" things, whose importance sometimes overrides the meaning of the content, is beyond the scope of this paper [56-58].

Information depends upon the model of care: paternalistic approaches "manoeuvre" patients towards the physician's opinions, and can be considered intrusive, while a purely informative model often lacks empathy and participation [57-65]. Personalizing medical care goes along with a holistic approach and with an individual patient-physician relationship. This model involves presenting information honestly but not necessarily impartially, an approach in which personal opinions are mitigated, discussed and critically reviewed. In this regard, the physician counsellor's role is to facilitate the expression of the patient's opinions, within an empathic relationship [66-72].

By definition, empathy cannot exist without pathos, nor can counselling without convictions.

In the case of $\mathrm{Mr}$. $\mathrm{H}$, we chose the dynamic interaction of therapeutic alliance: in this model, the physician not only offers a choice of all the feasible options (in this case, starting dialysis or continuing with supportive treatment), but discusses with the patient how to adapt the options to their needs and preferences. When using this model, the strategy chosen may be a compromise between the "best", or most validated option, and a reasonable, but more feasible one.

In the case of incremental dialysis, there is wide variability between specific modalities: while some authors hold that dialysis should be started with "soft" once-weekly sessions, others prefer a longer session, or define twice-weekly dialysis as incremental. In the absence of a validated, uniform way to perform this schedule, we adapted the initial policy to the patient's needs and concerns (being home to receive meals). While in his case the initial policy proved to be successful and the original schedule was followed for 1 year, the same dynamic approach could have been followed if additional adaptations or changes had been needed.

A further issue, that here is mentioned only in passing, on account of its extreme complexity, is the feasibility of a non-experiential choice in the exquisitely subjective field of "tolerance", in which an individual's response is nearly impossible to foresee a priori.

In this regard, a shared decision process also supports starting dialysis on a "trial basis", to test tolerance, and clinical advantages; no approach is without cost, but since the patient (see Table 1) had frequently been hospitalised, and was in an unstable metabolic balance, we considered that the risks of a dialysis trial (tunnelled catheter and dialysis start) were balanced by the expected benefit of improved metabolic stability.
The further implications regarding the beneficence/ non-maleficence balance will be discussed below.

\section{Beneficence}

The potential benefit of correcting the most troublesome metabolic derangements of severe CKD is obvious. In the case of $\mathrm{Mr}$. $\mathrm{H}$, whose glomerular filtration rate was around $5 \mathrm{~mL} / \mathrm{min}$, the presence of severe acidosis and the difficulty involved in managing the delicate balance between dehydration and fluid overload, were clear indications of the need for dialysis start.

Furthermore, while recent data challenge the policy of starting dialysis on the sole basis of a decreased glomerular filtration rate, whose reliability is uncertain in elderly patients, there is no doubt that dialysis can be successful in octogenarians and nonagenarians, especially if adapted to the needs and problems of this fragile population [73-76].

As will be further discussed, the problem may not be starting dialysis, but which dialysis should be started to maximize benefits, considering the patient's age and life expectancy.

The potential relationship between dialysis schedule, beneficence, and non-maleficence will be discussed in detail in the next section.

\section{Non-maleficence}

Dialysis is a prison: this harsh statement, recently published in a widely-read French newspaper, reflects the common opinion of this life-saving treatment [77]. There are several reasons why this statement may apply to dialysis patients; however, at least some of the oftencited tortures dialysis entails can be mitigated by a personalized schedule of incremental treatment.

In particular, post-dialysis fatigue is closely related to intradialytic shifts and intradialytic weight loss. The experience with short daily dialysis sessions shows that a shorter session is usually better tolerated, with an significant reduction in post-dialysis fatigue [18-25, 78-82].

If dialysis is highly intrusive in daily life, this is obviously also related to the number of sessions per week. While there is still no agreement on the definition of "incremental" dialysis, some U.S. experts presently suggest an approach based on twice-weekly dialysis $[18,19,83-85]$. In Italy, where it is often part of an integrated approach which includes nutritional management, dialysis start generally involves one session per week, while continuing the diet prescribed in the pre-dialysis phase (usually with a moderate protein restriction, at $0.6-0.8 \mathrm{~g} / \mathrm{Kg} /$ day) $[18-29,86]$. As $\mathrm{Mr}$. H was correctly following a low-protein diet, to minimize the risk of malnutrition, we chose this second option for starting dialysis. 
The slow progression of his chronic kidney disease, with good residual diuresis and lack of life-threatening episodes of ionic derangements (including hyperkalemia) further supported this approach [85-89].

No less importantly, as previously mentioned, an incremental dialysis start allowed us to perform a "dialysis test" for tolerance, and reach an experience-based decision on whether dialysis treatment should be continued, intensified or discontinued.

In our case we believe that the "treatment test" was the best way to overcome a potentially endless discussion on the advantages versus the drawbacks of the incremental dialysis policy that we had a priori identified as a clinically reasonable choice, in keeping with Mr. H's everyday routine and quality of life.

In fact, a single 3-h dialysis session per week might not correct fluid overload or acidosis; instead a moderately protein-restricted diet (which had been prescribed in the pre-dialysis phase, and had been compatible with preserved nutritional status) could induce malnutrition. Furthermore the presence of a vascular access, or the development of intradialytic or post-dialysis hypotension could have had a negative effect on quality of life and morbidity.

The biological variability of the "old-old" is well known, and, although several experiences of incremental dialysis have been published, the data are still too scant to supply exhaustive indications (nutritional approach in well-nourished 90-year-old patient previously on a low-protein diet).

The good results obtained in our patient, apparently thanks to the combined benefits of diet and dialysis, cannot of course be taken as an a posteriori demonstration of the efficacy of this policy; conversely, they do suggest that being flexible and adapting to the patient's needs means that an approach can be evaluated and adjusted as treatment progresses.

\section{The narrative analysis}

While principlist ethics offer a simple framework for analysing the clinical problem, a narrative approach enables us to identify solutions in individual cases, taking into account the patient's history, family support, fears and concerns, as well as daily life routine [33-35].

By definition, a narrativist tries to capture the stories that patients and their families tell or hide, and that, with silences as well as words, characterize decision-making [33]. Narrativism brings flexibility and personalization into the discussion and helps mitigate rigid reasoning based on the four principles, by introducing inventive solutions and practical strategies, such as changing the time of meal delivery, or scheduling dialysis sessions early to allow $\mathrm{Mr}$. $\mathrm{H}$ to be home in time for lunch [90-92]. Furthermore, a narrative approach seeks to identify the fears or problems behind the facts, in this case, Mr. H's fear of changing the rhythm of his daily life and losing autonomy.

The history of our patient reflects the need for a flexible approach adapted to his needs that takes into consideration the importance different individuals attribute to the constraints of daily life. A problem with the home delivery of hot meals may seem trivial in comparison to living or dying, but can appear as unsolvable to an elderly individual, becoming the focus of their fears and concerns. In this regard, finding pragmatic solutions is not only a way to come to grips with a specific inconvenience, but also shows the patient that problems can be solved and dialysis can be adapted to their needs and wishes, and need not be "a prison".

\section{Combining principlism and narrative analysis}

In terms of a principlist analysis, it seemed likely that $\mathrm{Mr}$. $\mathrm{H}$ would benefit from a flexible approach to dialysis, which would serve to overcome his health problems (benefit: clinical stabilisation in the context of a uremic syndrome with difficulty in attaining a stable clinical balance with non-dialytic conservative care). Attention to minimizing side effects (non-maleficence) led to the choice of an incremental dialysis approach, in a setting in which the principle of justice was respected, at least for treatment availability (no competition with other patients who also needed dialysis). While the physicians were mainly concerned with finding the best compromise between beneficence and non-maleficence, the patient was worried about the disruption of his daily routine (home-delivered meals). While he was not a priori against dialysis (he had initially accepted it), he subsequently refused treatment because "If I'm not home... I won't have anything to eat".

A rigid interpretation of autonomy would probably have led to his not starting dialysis (the patient was informed, competent, and free to choose); inquiring in detail about what had made him change his mind, and asking about his habits and quality of life, identified a problem (missing meal delivery) and found pragmatic solutions that did not impact on clinical aspects, but modulated the individual's choice (autonomy). Narrativism allowed us to get a detailed picture of the patient and mitigated the rigidity of the four principles; while many of the considerations regarding dialysis start could apply to other elderly patients with end-stage kidney disease, the patient's choice was unique to $\mathrm{Mr}$. $\mathrm{H}$, as the solution also was.

In this regard, we suggest that principlism allows us to arrive at an initial analysis of difficult cases, identifying the specific aspects of the problems involved, while narration serves to put problems in perspective and possibly solve them. 


\section{Discussion and conclusions}

The case discussed illustrates the limits of a Manichean contraposition between dialysis and palliative care.

In this extreme balance, dialysis is intended as "renal replacement therapy" (RRT), a treatment that has to deliver, regardless of the residual renal function, full artificial depuration. While the definition of "adequate" and "optimal" dialysis is not clear, a strict "RRT approach" ignores residual renal function, in spite of the fact that its presence is one of the most important survival markers [18, 25-27, 87-89].

Palliative-conservative care is defined as a comprehensive treatment which allows for reasonable survival, with a good quality of life, without dialysis [10-14]. However, it is not clear why we should not offer this to all patients, and start dialysis only when an acceptable clinical balance can no longer be maintained using conservative treatment.

Indeed, this sharp opposition between palliativeconservative care and dialysis, which is often thought to be unavoidable, has begun to be seen as less of a contrast, and what is now being proposed is the integration of the two in what is called kidney supportive care, aimed at improving the quality of life, whenever possible together with therapies intended to prolong life, such as dialysis. Furthermore, the term palliative dialysis is also occasionally used to indicate a form of patient-centered dialysis that focuses on quality of life.

In our case, the decision to start dialysis was postponed until the time when "conservative care" could no longer ensure well-being. The once-weekly session was started to correct acidosis, reduce overload, and allow some degree of correction of uremic intoxication. The interventions were graduated to clinical context and life expectancy, and their purpose was to correct the derangements associated with short-term clinical problems (acidosis and overload).

The contraposition between RRT and palliativeconservative care points to what is now called "transition" to dialysis [11-14]. Studies on the high risk of death during the first months of dialysis deal with an abrupt transition from pre-dialysis care to thrice weekly 4-h haemodialysis sessions (or to a "full" schedule on peritoneal dialysis).

The choice of starting a "full schedule" of dialysis is often the only one possible in patients with minimal or no predialysis follow-up that start dialysis when admitted to the emergency room. However, in patients who have been consistently followed, the best choice may be to progressively increase their scheduled visits, from every 3 months to once a month to weekly, to a onceweekly dialysis sessions.

The case of Mr. H, in which the availability of a "soft" dialysis start smoothed the terms of a tough ethical dilemma, without forcing us to sacrifice quality to quantity of life, is a story with a happy ending, at least for the time being: our patient is doing well on dialysis, enjoys his role as our "oldest patient", gets home by the time his meal is delivered, and tolerates dialysis sessions well.

Concerned about his daily routine, Mr. $\mathrm{H}$ would not have accepted more intrusive treatment which, as his story shows, was not really needed; his positive experience with dialysis will modulate his further choices, including intensifying dialysis, if need be.

In conclusion, this case encourages us to reflect on the reasons why laypeople and many physicians have a negative view of dialysis. Is dialysis in itself a killer, or is the way we use this treatment the cause of "dialysis shock"?

Unlike standardized medicine, based on identifying the best solution, in an ethical discussion there is no best solution, but instead a personalized choice adapted to the context and to the individual. As in chemotherapy, in which protocols are increasingly being adapted to patients, there is room and a need for well-grounded "personalized medicine" in renal replacement therapy.

\section{Abbreviations}

CKD: Chronic kidney disease; ESRD: End stage renal disease; RRT: Renal replacement therapy

\section{Acknowledgements}

To Susan Finnel for her careful language review.

Funding

No funding was obtained for this study.

Availability of data and materials

Individual data of the patient is available upon request.

Authors' contributions

GBP and JPC followed the patient; GBP and ACS drafted the paper and performed the bibliographic search; all authors approved the final version.

Ethics approval and consent to participate Not applicable.

\section{Consent for publication}

Written informed consent was obtained from the patient for publication of this Case Report and any accompanying images. A copy of the written consent is available for review by the Editor of this journal.

\section{Competing interests}

We confirm that we have read BioMed Central's guidance on competing interests: GBP is on the advisory board of Ketosteril, and has received travel funds and an unrestricted sponsorship to the University of Torino. The other authors have no competing interests for this case.

\section{Publisher's Note}

Springer Nature remains neutral with regard to jurisdictional claims in published maps and institutional affiliations.

Received: 9 July 2017 Accepted: 31 October 2017

Published online: 09 November 2017

References

1. Thorsteinsdottir B, Swetz KM, Albright RC. The ethics of chronic dialysis for the older patient: time to Reevaluate the norms. Clin J Am Soc Nephrol. 2015;10(11):2094-9. 
2. Thorsteinsdottir B, Swetz KM, Tilburt JC. Dialysis in the frail elderly-a current ethical problem, an impending ethical crisis. J Gen Intern Med. 2013; 28:1511-6.

3. Muthalagappan S, Johansson L, Kong WM, Brown EA. Dialysis or conservative care for frail older patients: ethics of shared decision-making. Nephrol Dial Transplant. 2013;28(11):2717-22.

4. Swidler M. Considerations in starting a patient with advanced frailty on dialysis: complex biology meets challenging ethics. Clin J Am Soc Nephrol. 2013;8:1421-8

5. Rosansky S, Glassock RJ, Clark WF. Early start of dialysis: a critical review. Clin J Am Soc Nephrol. 2011;6(5):1222-8

6. Rosansky SJ. The sad truth about early initiation of dialysis in elderly patients. JAMA. 2012;307:1919-20.

7. Brown MA, Collett GK, Josland EA, Foote C, Li Q, Brennan FP. CKD in elderly patients managed without dialysis: survival, symptoms, and quality of life. Clin J Am Soc Nephrol. 2015;10(2):260-8.

8. Jassal SV. Four plus forty-four: hours to modify, theirs to enjoy. Clin J Am Soc Nephrol. 2015;10(2):169-71.

9. Murtagh FE, Marsh JE, Donohoe P, Ekbal NJ, Sheerin NS, Harris FE. Dialysis or not? A comparative survival study of patients over 75 years with chronic kidney disease stage 5. Nephrol Dial Transplant. 2007;22:1955-62.

10. Carson RC, Juszczak M, Davenport A, Burns A. Is maximum conservative management an equivalent treatment option to dialysis for elderly patients with significant comorbid disease? Clin J Am Soc Nephrol. 2009;4:1611-9.

11. Chandna SM, Da Silva-Gane M, Marshall C, Warwicker P, Greenwood RN, Farrington K. Survival of elderly patients with stage 5 CKD: comparison of conservative management and renal replacement therapy. Nephrol Dial Transplant. 2011;26:1608-14.

12. Foote C, Hussain JA, Mooney A, Russon L. Comparison of survival analysis and palliative care involvement in patients aged over 70 years choosing conservative management or renal replacement therapy in advanced chronic kidney disease. Palliat Med. 2013;27:829-39.

13. Raghavan D, Holley JL. Conservative Care of the Elderly CKD patient: a practical guide. Adv Chronic Kidney Dis. 2016;23(1):51-6.

14. Foote C, Kotwal S, Gallagher M, Cass A, Brown M, Jardine M. Survival outcomes of supportive care versus dialysis therapies for elderly patients with end-stage kidney disease: a systematic review and meta-analysis. Nephrology (Carlton). 2016;21:241-53.

15. Piccoli GB, Nazha M, Capizzi I, Vigotti FN, Scognamiglio S, Consiglio V, Mongilardi E, Bilocati M, Avagnina P, Versino E. Diet as a system: an observational study investigating a multi-choice system of moderately restricted low-protein diets. BMC Nephrol. 2016;17(1):197.

16. Piccoli GB, Nazha M, Capizzi I, Vigotti FN, Mongilardi E, Bilocati M, Avagnina $P$, Versino $E$. Patient survival and costs on moderately restricted low-protein diets in advanced CKD: equivalent survival at lower costs? Nutrients. 2016; 8(12):E758

17. Piccoli GB, Capizzi I, Vigotti FN, Leone F, D'Alessandro C, Giuffrida D, Nazha M, Roggero S, Colombi N, Mauro G, Castelluccia N, Cupisti A, Avagnina P. Low protein diets in patients with chronic kidney disease: a bridge between mainstream and complementary-alternative medicines? BMC Nephrol. 2016; 17(1):76.

18. Obi Y, Chou J, Kalantar-Zadeh K. Introduction to the critical balance-residual kidney function and incremental transition to dialysis. Semin Dial. 2017; https://doi.org/10.1111/sdi.12600. [Epub ahead of print]

19. Ghahremani-Ghajar M, Rojas-Bautista V, Lau WL, Pahl M, Hernandez M, Jin A, Reddy U, Chou J, Obi Y, Kalantar-Zadeh K, Rhee CM. Incremental Hemodialysis: the University of California Irvine experience. Semin Dial. 2017 Mar 14; https://doi.org/10.1111/sdi.12591. [Epub ahead of print]

20. Locatelli F, Del Vecchio L, Aicardi V. Nutritional issues with incremental dialysis: the role of low-protein diets. Semin Dial. 2017; https://doi.org/10. 1111/sdi.12585. [Epub ahead of print]

21. Park Jl, Park JT, Kim YL, Kang SW, Yang CW, Kim NH, Oh YK, Lim CS, Kim YS. Lee JP; CRC for ESRD investigators. Comparison of outcomes between the incremental and thrice-weekly initiation of hemodialysis: a propensitymatched study of a prospective cohort in Korea. Nephrol Dial Transplant. 2017;32(2):355-63. https://doi.org/10.1093/ndt/gfw332.

22. Locatelli F, Andrulli S, Pontoriero G, Di Filippo S, Bigi MC. Supplemented lowprotein diet and once-weekly hemodialysis. Am J Kidney Dis. 1994;24(2):192-204.

23. Bolasco P, Cupisti A, Locatelli F, Caria S, Kalantar-Zadeh K. Dietary Management of Incremental Transition to dialysis therapy: once-weekly Hemodialysis combined with low-protein diet. J Ren Nutr. 2016;26(6):352-9.
24. Caria S, Cupisti A, Sau G, Bolasco P. The incremental treatment of ESRD: a low-protein diet combined with weekly hemodialysis may be beneficial for selected patients. BMC Nephrol. 2014;15:172.

25. Fernández-Lucas M, Teruel-Briones JL, Gomis-Couto A, Villacorta-Pérez J, Quereda-Rodríguez-Navarro C. Maintaining residual renal function in patients on haemodialysis: 5-year experience using a progressively increasing dialysis regimen. Nefrologia. 2012;32(6):767-76.

26. Teruel-Briones JL, Fernández-Lucas M, Rivera-Gorrin M, Ruiz-Roso G, DíazDomínguez M, Rodríguez-Mendiola N, Quereda-Rodríguez-Navarro C. Progression of residual renal function with an increase in dialysis: haemodialysis versus peritoneal dialysis. Nefrologia. 2013;33(5):640-9.

27. Piccoli GB, Burdese M, Quaglia M, Mezza E, Pacitti A, Maffei S, Fenoglio R, Fop F, Jeantet A, Grassi G, Dani F, Segoloni GP. Tailored dialysis for diabetic patients: a tool for autonomy and efficiency. Perit Dial Int. 2002;22(4):531-4

28. Piccoli GB, Motta D, Gai M, Mezza E, Maddalena E, Bravin M, Tattoli F, Consiglio V, Burdese M, Bilucaglia D, Ferrari A, Segoloni GP. Tailored dialysis start may allow persistence of residual renal function after graft failure: a case report. Transplant Proc. 2004;36(9):2607-9.

29. Piccoli GB, Burdese M, Mezza E, Consiglio V, Mangiarotti G, Thea A, Bermond F, Gai M, Lanfranco G, Jeantet A, Segoloni GP. Maintenance of residual renal function 10 years after the start of hemodialysis: the advantage of tailored schedules? Int J Artif Organs. 2004;27(3):251-4.

30. Broers NJ, Cuijpers AC, van der Sande FM, Leunissen KM, Kooman JP. The first year on haemodialysis: a critical transition. Clin Kidney J. 2015; 8(3):271-7.

31. Schumann JH, Alfandre D. Clinical ethical decision making: the four topics approach. Semin Med Pract. 2008;11:36-42. Available at http://citeseerx.ist. psu.edu/viewdoc/download;jsessionid=CFB55C208EBCE88B309534965A6BB 411?doi=10.1.1.360.1143\&rep=rep1\&type=pdf. Accessed 5 Nov 2017.

32. Iltis AS. Bioethics as methodological case resolution: specification, specified principlism and casuistry. J Med Philos. 2000;25(3):271-84.

33. McCarthy J. Principlism or narrative ethics: must we choose between them? Med Humanit. 2003:29(2):65-71.

34. Montello M. Narrative ethics. Hast Cent Rep. 2014;44(1 Suppl):S2-6.

35. Jones AH. Narrative ethics, narrative structure. Hast Cent Rep. 2014;44(1 Suppl):S32-5.

36. Yarborough $M$. Deciding for others at the end of life: storytelling and moral agency. J Clin Ethics. 2005;16:127-43.

37. Jansen LA. Between beneficence and justice: the ethics of stewardship in medicine. J Med Philos. 2013 Feb;38(1):50-63.

38. Kelleher JP. Beneficence, justice, and health care. Kennedy Inst Ethics J. 2014;24(1):27-49.

39. Veatch RM. Justice in health care: the contribution of Edmund Pellegrino. J Med Philos. 1990;15(3):269-87.

40. Ruger JP. Health, capability, and justice: toward a new paradigm of health ethics, policy and law. Cornell J Law Public Policy. 2006;15(2):403-82.

41. Pratt B, Hyder AA. Fair resource allocation to Health Research: priority topics for bioethics scholarship. Bioethics. 2017; https://doi.org/10.1111/ bioe. 12350

42. Rosoff PM. Who should ration? AMA J Ethics. 2017:19(2):164-73.

43. Carter D, Gordon J, Watt AM. Competing principles for allocating health care resources. J Med Philos. 2016:41(5):558-83.

44. Gheaus A. Solidarity, justice and unconditional access to healthcare. J Med Ethics. 2017:43(3):177-81.

45. Kurella M, Covinsky KE, Collins AJ, Chertow GM. Octogenarians and nonagenarians starting dialysis in the United States. Ann Intern Med. 2007; 146(3):177-83.

46. Sladoje-Martinovic B, Mikolasevic I, Bubic I, Racki S, Orlic L. Survival of chronic hemodialysis patients over 80 years of age. Clin Interv Aging. 2014:9:689-96.

47. Kan WC, Wang JJ, Wang SY, Sun YM, Hung CY, Chu CC, Lu CL, Weng SF, Chio CC, Chien CC. The new comorbidity index for predicting survival in elderly dialysis patients: a long-term population-based study. PLoS One. 2013;8(8):e68748.

48. Lin YT, Wu PH, Kuo MC, Lin MY, Lee TC, Chiu YW, Hwang SJ, Chen HC. High cost and low survival rate in high comorbidity incident elderly hemodialysis patients. PLoS One. 2013:8(9):e75318.

49. Butler CR, Mehrotra R, Tonelli MR, Lam DY. The evolving ethics of dialysis in the United States: a Principlist bioethics approach. Clin J Am Soc Nephrol. 2016;11(4):704-9. 
50. Sanders JJ, Chow V, Enzinger AC, Lam TC, Smith PT, Quiñones R, Baccari A, Philbrick S, White-Hammond G, Peteet J, Balboni TA, Balboni MJ. Seeking and accepting: U.S. clergy theological and moral perspectives informing decision making at the end of life. J Palliat Med. 2017; https://doi.org/10. 1089/jpm.2016.0545.

51. Bandini II, Courtwright A, Zollfrank AA, Robinson EM, Cadge W. The role of religious beliefs in ethics committee consultations for conflict over lifesustaining treatment. J Med Ethics. 2017;43:353. pii: medethics-2016-103930

52. Gabbay E, McCarthy MW, Fins JJ. The Care of the Ultra-Orthodox Jewish Patient. J Relig Health. 2017;56(2):545-60.

53. Padela Al, Qureshi O. Islamic perspectives on clinical intervention near the end-of-life: We can but must we? Med Health Care Philos. 2016. [Epub ahead of print].

54. Holm S. Not just autonomy-the principles of American biomedical ethics. J Med Ethics. 1995;21(6):332-8.

55. Gillon R. Ethics needs principles-four can encompass the rest-and respect for autonomy should be "first among equals". J Med Ethics. 2003;29(5):307-12.

56. Bester J, Cole CM, Kodish E. The limits of informed consent for an overwhelmed patient: Clinicians' role in protecting patients and preventing overwhelm. AMA J Ethics. 2016;18(9):869-86.

57. Webster RK, Weinman J, Rubin GJ. A systematic review of factors that contribute to nocebo effects. Health Psychol. 2016;35(12):1334-55.

58. Leclercq $V$. Benevolent lies and divine truths: information-giving practices in the era of medical paternalism, Brussels (1870-1930). Gesnerus. 2016;73(1): 123-47.

59. Vučemilović M, Mahmić-Kaknjo M, Pavličević I. Transition from paternalism to shared decision making - a review of the educational environment in Bosnia and Herzegovina and Croatia. Acta Med Acad. 2016;45(1):61-9.

60. Hansen PG, Skov LR, Skov KL. Making healthy choices easier: regulation versus nudging. Annu Rev Public Health. 2016;37:237-51.

61. Long BD, Shuman AG. Could good care mean withholding information from patients? AMA J Ethics. 2016;18(1):6-11.

62. Berger JT. Redefining the domains of decision making by physician and patient. Int J Clin Pract. 2011;65(8):828-30.

63. Cutcliffe JR, Cassedy P. The development of empathy in students on a short, skills based counselling course: a pilot study. Nurse Educ Today. 1999;19(3): 250-7.

64. Shattell MM. Engaging students and faculty with diverse first-person experiences: use of an interpretive research group. J Nurs Educ. 2007;46(12): 572-5.

65. Xiao B, Huang C, Imel ZE, Atkins DC, Georgiou P, Narayanan SS. A technology prototype system for rating therapist empathy from audio recordings in addiction counseling. PeerJ Comput Sci. 2016:e59. https://doi. org/10.7717/peerj-cs.59.

66. Thaler RH, Sunstein CR. Nudge: Improving decisions about health, wealth, and happiness. New Haven: Yale University Press; 2008. p. 1-293.

67. Pagès-Puigdemont N, Mangues MA, Masip M, Gabriele G, FernándezMaldonado L, Blancafort S, Tuneu L. Patients' perspective of medication adherence in chronic conditions: a qualitative study. Adv Ther. 2016 Oct; 33(10):1740-54.

68. Laws HB, Constantino MJ, Sayer AG, Klein DN, Kocsis JH, Manber R, Markowitz JC, Rothbaum BO, Steidtmann D, Thase ME, Arnow BA. Convergence in patient-therapist therapeutic alliance ratings and its relation to outcome in chronic depression treatment. Psychother Res. 2016;1:1-15.

69. Goldsmith LP, Dunn G, Bentall RP, Lewis SW, Wearden AJ. Therapist effects and the impact of early therapeutic alliance on symptomatic outcome in chronic fatigue syndrome. PLoS One. 2015;10(12):e0144623.

70. Gambaro G. Dealing with chronic disease: the need for a therapeutic alliance with the patient. G Ital Nefrol. 2007;24(2):102-3.

71. Ronco C, Mason G, Nayak Karopadi A, Milburn A, Hegbrant J. Healthcare systems and chronic kidney disease: putting the patient in control. Nephrol Dial Transplant. 2014;29(5):958-63.

72. Methven S, Caskey F. Putting the patient first: should we nudge them or shove them? Nephrol Dial Transplant. 2014;29(5):941-3.

73. Obrador GT, Pereira BJ. Early referral to the nephrologist and timely initiation of renal replacement therapy: a paradigm shift in the management of patients with chronic renal failure. Am J Kidney Dis. 1998; 31(3):398-417.

74. Leurs $P$, Machowska A, Lindholm B. Timing of dialysis initiation: when to start? Which treatment? J Ren Nutr. 2015;25(2):238-41.
75. Liberek T, Warzocha A, Galgowska J, Taszner K, Clark WF, Rutkowski B. When to initiate dialysis-is early start always better? Nephrol Dial Transplant. 2011; 26(7):2087-91.

76. Nesrallah GE, Mustafa RA, Clark WF, Bass A, Barnieh L, Hemmelgarn BR, Klarenbach S, Quinn RR, Hiremath S, Ravani P, Sood MM, Moist LM. Canadian Society of Nephrology. Canadian Society of Nephrology 2014 clinical practice guideline for timing the initiation of chronic dialysis. CMAJ. 2014;186(2):112-7.

77. http://www.lemonde.fr/sciences/article/2016/05/16/la-dialyse-est-une-prisonallegeons-les-peines_4920416_1650684.html. Accessed 5 Nov 2017.

78. Oliver V, Stephenson M. Prevention, assessment and management of postdialysis fatigue in patients attending in-center hemodialysis: a best practice implementation project. JBI Database System Rev Implement Rep. 2016; 14(11):278-88.

79. Horigan AE, Barroso JV. A comparison of temporal patterns of fatigue in patients on Hemodialysis. Nephrol Nurs J. 2016;43(2):129-38. 148; quiz 139

80. Twardowski ZJ. Treatment time and ultrafiltration rate are more important in dialysis prescription than small molecule clearance. Blood Purif. 2007; 25(1):90-8.

81. Morfin JA, Fluck RJ, Weinhandl ED, Kansal S, McCullough PA, Komenda P. Intensive Hemodialysis and treatment complications and tolerability. Am J Kidney Dis. 2016:68(5S1):S43-50.

82. Bossola M, Vulpio C, Tazza L. Fatigue in chronic dialysis patients. Semin Dial. 2011:24(5):550-5

83. Yan Y, Ramirez S, Anand S, Qian J, Zuo L. Twice-weekly Hemodialysis in China: can it be a better option for initiation or maintenance dialysis therapy? Semin Dial. 2017; https://doi.org/10.1111/sdi.12588.

84. Obi Y, Kalantar-Zadeh K, Streja E, Daugirdas JT. Prediction equation for calculating residual kidney urea clearance using urine collections for different hemodialysis treatment frequencies and interdialytic intervals. Nephrol Dial Transplant. 2017. doi:10.1093/ndt/gfw473. [Epub ahead of print]

85. Fan Q, Yan Y, Gu L, He L, Chen N, Jiang G, Yuan L, Xue J, Zhang Y, Ma J, Jin H, Yuan W, Guo Z, Guo L, Wang N, Zhang W, Ye Z, Mao P, Pi X, Lu R, Zhu M, Zhang W, Ni Z, Qian J, Pang H. Prognostic value of the delivery dialysis dose on twice-weekly Hemodialysis patients. Am J Nephrol. 2017; 45(3):273-82.

86. Bellizzi V Cupisti A, Locatelli F, Bolasco P, Brunori G, Cancarini G, Caria S, De Nicola L, Di lorio BR, Di Micco L, Fiaccadori E, Garibotto G, Mandreoli M, Minutolo R, Oldrizzi L, Piccoli GB, Quintaliani G, Santoro D, Torraca S, Viola BF. "Conservative Treatment of CKD" study group of the Italian Society of Nephrology. Low-protein diets for chronic kidney disease patients: the Italian experience. BMC Nephrol. 2016;17(1):77.

87. Savla D, Chertow GM, Meyer T, Anand S. Can twice weekly hemodialysis expand patient access under resource constraints? Hemodial Int. 2017;21(4): 445-52.

88. Basile C, Casino FG, Kalantar-Zadeh K. Is incremental hemodialysis ready to return on the scene? From empiricism to kinetic modelling. J Nephrol. 2017; https://doi.org/10.1007/s40620-017-0391-0.

89. Merino JL, Domínguez P, Bueno B, Amézquita $Y$, Espejo B, Paraíso V. Application of a pattern of incremental haemodialysis, based on residual renal function, when starting renal replacement therapy. Nefrologia. 2017; 37(1):39-46.

90. Charon R. The patient-physician relationship. Narrative medicine: a model for empathy, reflection, profession, and trust. JAMA. 2001;286(15):1897-902.

91. Charon R. Narrative medicine: form, function, and ethics. Ann Intern Med. 2001;134(1):83-7.

92. Rosti G. Role of narrative-based medicine in proper patient assessment. Support Care Cancer. 2017;25(Suppl 1):3-6. 